\title{
Uniaxial negative thermal expansion and metallophilicity in $\mathrm{Cu}_{3}\left[\mathrm{Co}(\mathrm{CN})_{6}\right]$
}

\author{
A.F. Sapnik ${ }^{\mathrm{a}}$, X. Liu ${ }^{\mathrm{b}}$, H.L.B. Boström ${ }^{\mathrm{a}}$, C.S. Coates ${ }^{\mathrm{a}}$, A.R. Overy ${ }^{\mathrm{a}, \mathrm{c}}$, E.M. Reynolds ${ }^{\mathrm{a}}$, \\ A. Tkatchenko ${ }^{\mathrm{d}}$, A.L. Goodwin ${ }^{\mathrm{a}, *}$ \\ a Department of Chemistry, University of Oxford, Inorganic Chemistry Laboratory, South Parks Road, Oxford OX1 3QR, UK \\ b State Key Laboratory of Mechanics and Control of Mechanical Structures, Key Laboratory for Intelligent Nano Materials and Devices of Ministry of \\ Education, Nanjing University of Aeronautics and Astronautics, Nanjing 210016, China \\ ${ }^{\mathrm{c}}$ Diamond Light Source, Chilton, Oxfordshire OX11 ODE, UK \\ d Physics and Materials Science Research Unit, University of Luxembourg, L-1511, Luxembourg
}

\section{A R T I C L E I N F O}

Keywords:

Negative thermal expansion

Framework materials

Metallophilic interactions

\begin{abstract}
A B S T R A C T
We report the synthesis and structural characterisation of the molecular framework copper(I) hexacyanocobaltate(III), $\mathrm{Cu}_{3}\left[\mathrm{Co}(\mathrm{CN})_{6}\right]$, which we find to be isostructural to $\mathrm{H}_{3}\left[\mathrm{Co}(\mathrm{CN})_{6}\right]$ and the colossal negative thermal expansion material $\mathrm{Ag}_{3}\left[\mathrm{Co}(\mathrm{CN})_{6}\right]$. Using synchrotron X-ray powder diffraction measurements, we find strong positive and negative thermal expansion behaviour respectively perpendicular and parallel to the trigonal crystal axis: $\alpha_{a}=25.4(5) \mathrm{MK}^{-1}$ and $\alpha_{c}=-43.5(8) \mathrm{MK}^{-1}$. These opposing effects collectively result in a volume expansivity $\alpha_{V}=7.4(11) \mathrm{MK}^{-1}$ that is remarkably small for an anisotropic molecular framework. This thermal response is discussed in the context of the behaviour of the analogous H- and Ag-containing systems. We make use of density-functional theory with many-body dispersion interactions (DFT + MBD) to demonstrate that $\mathrm{Cu}^{+} \ldots \mathrm{Cu}^{+}$metallophilic ('cuprophilic') interactions are significantly weaker in $\mathrm{Cu}_{3}\left[\mathrm{Co}(\mathrm{CN})_{6}\right]$ than $\mathrm{Ag}^{+} \ldots \mathrm{Ag}^{+}$interactions in $\mathrm{Ag}_{3}\left[\mathrm{Co}(\mathrm{CN})_{6}\right]$, but that this lowering of energy scale counterintuitively translates to a more moderate-rather than enhanced-degree of structural flexibility. The same conclusion is drawn from consideration of a simple GULP model, which we also present here. Our results demonstrate that strong interactions can actually be exploited in the design of ultra-responsive materials if those interactions are set up to act in tension.
\end{abstract}

\section{Introduction}

The development of responsive materials often exploits weak interactions as key design elements because lower interaction energies heighten the sensitivity of a material to external perturbations [1-4]. It is no accident, for example, that the weak inter-molecular forces in molecular crystals generally allow more extreme responses to changes in temperature $[5,6]$ and pressure $[7,8]$ than is possible in conventional inorganic ceramics, the structures of which are held together by strong ionic and covalent bonding networks. In this context, supramolecular interactions assume a particular importance, given that their energy scales are so much lower than those of electrostatic or covalent interactions. Hence the prevalence of hydrogen-bonding [9], halogenbonding [10], $\pi-\pi$ [11], van der Waals (vdW) [5], host-guest [12,13], and metallophilic [14] interactions amongst many of the important materials in the field.

Thermal expansion behaviour is a straightforward measure of responsiveness: it quantifies the effect of temperature on the linear dimensions of a material [15]. Compounds with large thermal expansion coefficients often show extreme and counterintuitive responses to pressure [16,17], and may harbour various other anomalous elastic properties, such as negative Poisson's ratios [18] or thermosalient effects $[19,20]$. So it is perhaps unsurprising that some of the most extreme ('colossal') thermal expansion known has been observed in framework materials whose lattice dimensions are a function of weak metallophilic interactions $[14,17,21]$. The canonical system of this type is $\mathrm{Ag}_{3}\left[\mathrm{Co}(\mathrm{CN})_{6}\right]$, which adopts a lattice structure [22] that can flex in such a way as to vary argentophilic $\mathrm{Ag}^{+} . . . \mathrm{Ag}^{+}$separations without affecting covalent interactions within the lattice itself [23,24]. A geometric consequence of this flexing behaviour is that the positive thermal expansion (PTE) of argentophilic interactions (i.e. increase in separation with increasing temperature) is translated into a negative thermal expansion (NTE) effect in a perpendicular direction, Fig. 1. The same mechanism operates under application of hydrostatic pressure, such that volume compression actually results in linear expansion for a particular set of directions [17]-so-called negative

\footnotetext{
* Corresponding author.

E-mail address: andrew.goodwin@chem.ox.ac.uk (A.L. Goodwin).
} 


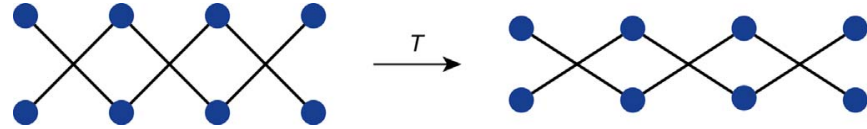

Fig. 1. "Wine-rack" mechanism for anisotropic thermal expansion in flexible framework materials. Horizontal expansion couples to vertical contraction via lattice flexing.

linear compressibility (NLC) [25-27]. NTE and NLC are valuable material properties, exploitable in the design of a thermal composites used in optical devices and next-generation pressure sensors.

In seeking to design even more responsive analogues of $\mathrm{Ag}_{3}\left[\mathrm{Co}(\mathrm{CN})_{6}\right]$, we considered the possibility of replacing $\mathrm{Ag}$ by $\mathrm{Cu}$. Metallophilic interactions involving $\mathrm{Cu}^{+}$ions are perhaps less well studied than argentophilic and aurophilic interactions, but are expected to be weaker given the reduced polarisability of the $3 d$ shell $[28,29]$. Hence, by the arguments discussed above, $\mathrm{Cu}_{3}\left[\mathrm{Co}(\mathrm{CN})_{6}\right]$ has always been an obvious candidate for extreme thermomechanical response. To the best of our knowledge, this system has never previously been reported: the difficulty of preparing the phase is likely a consequence of the propensity for $\mathrm{Cu}^{+}$to disproportionate under the aqueous reaction conditions used to prepare the family of materials related to $\mathrm{Ag}_{3}\left[\mathrm{Co}(\mathrm{CN})_{6}\right]$ [23]. We have recently exploited the $\mathrm{Cu}^{2+}$ reduction protocol developed in Ref. [30] to allow access to otherwise unrealisable $\mathrm{Cu}(\mathrm{I})$-containing frameworks [31], suggesting that a similar synthetic approach may provide an alternative synthetic entry point to $\mathrm{Cu}_{3}\left[\mathrm{Co}(\mathrm{CN})_{6}\right]$.

Here we validate such an approach, reporting the synthesis, crystal structure, and thermal expansion behaviour of $\mathrm{Cu}_{3}\left[\mathrm{Co}(\mathrm{CN})_{6}\right]$. Using a combination of high-resolution synchrotron X-ray diffraction measurements and Rietveld refinement, we show the system to be isostructural with $\mathrm{Ag}_{3}\left[\mathrm{Co}(\mathrm{CN})_{6}\right]$ and $\mathrm{H}_{3}\left[\mathrm{Co}(\mathrm{CN})_{6}\right]$ [22,32-34]. Variable-temperature (100-598 K) X-ray diffraction measurements allow determination of the corresponding coefficients of thermal expansion $\alpha_{\ell}=(\partial \ln \ell / \partial T)_{p}$, which we find to be substantially less extreme than those of $\mathrm{Ag}_{3}\left[\mathrm{Co}(\mathrm{CN})_{6}\right]$ (even if they remain large in the context of the behaviour of conventional inorganic solids [35]). In particular, our data give $\alpha_{a}=25.4(5) \mathrm{MK}^{-1}$ and $\alpha_{c}=-43.5(8) \mathrm{MK}^{-1}$; cf $\alpha_{a}=144(9) \mathrm{MK}^{-1}$ and $\alpha_{c}=-126(4) \mathrm{MK}^{-1}$ for $\mathrm{Ag}_{3}\left[\mathrm{Co}(\mathrm{CN})_{6}\right]$ [23]. In order to rationalise this more moderate thermomechanical response in terms of the relative strengths of $\mathrm{Cu}^{+} \ldots \mathrm{Cu}^{+}$and $\mathrm{Ag}^{+} \ldots \mathrm{Ag}^{+}$metallophilic interactions, we carry out a series of $a b$ initio calculations. Our analysis suggests (i) that cuprophilic interactions are indeed weaker than argentophilic interactions in this family, and (ii) the more extreme thermomechanical response of the Ag-containing compound is a result of the balance of metallophilic and electrostatic interaction energies rather than a signature of particularly weak argentophilicity. Calculations using a highly simplified interaction model relevant to the entire $\mathrm{A}_{3}\left[\mathrm{Co}(\mathrm{CN})_{6}\right]$ structural family lead to the same conclusions. Our results suggest that competing interactions-rather than low-energy interactions per secan be key in the design of ultra-responsive materials.

\section{Methods}

All reagents were obtained from commercial suppliers and used as received.

\subsection{Copper(I) hexacyanocobaltate(III)}

We prepared polycrystalline samples of copper(I) hexacyanocobaltate(III) following a modification of the reduction protocol reported in Refs. [30,31]. A saturated aqueous solution of copper(II) sulfate (Sigma Aldrich, 99\%; $0.177 \mathrm{~g}$ ) was added dropwise to a concentrated aqueous solution of sodium bisulfite (Sigma Aldrich, $0.058 \mathrm{~g}$ ), present in stoichiometric excess, to afford a mint-green solution. The solution was stirred for $30 \mathrm{~min}$, after which time an aqueous solution of potassium hexacyanocobaltate(III) (Sigma Aldrich,
97\%, $0.123 \mathrm{~g}$; stoichiometric with respect to copper) was added dropwise to afford a pale blue precipitate. The solution was stirred for a further $2 \mathrm{~h}$, and the pale-blue solid product formed was isolated by filtration, washing $\left(\mathrm{H}_{2} \mathrm{O}\right)$ and drying under vacuum. The solid contained a mixture of copper(I) hexacyanocobaltate(III) and Prussian-blue-structured potassium copper(II) hexacyanocobaltate(III), a seemingly inescapable byproduct of this synthetic strategy.

Copper(I) hexacyanocobaltate(III) could also be obtained in impure form using mechanochemical synthesis. Stoichiometric quantities of solid tetrakis(acetonitrilo)copper(I) hexafluorophosphate (Chem Cruz, 98\%, $0.413 \mathrm{~g}$ ) and potassium hexacyanocobaltate (Sigma Aldrich, 97\%, $0.123 \mathrm{~g}$ ) were combined in an agate mortar, and intimately mixed via solid-state grinding for $30 \mathrm{~min}$. An obvious colour change from white to pale blue occurred during this process. The resulting solid was washed $\left(\mathrm{H}_{2} \mathrm{O}\right)$ and dried to afford a mixture of copper(I) hexacyanocobaltate(III), potassium copper(II) hexacyanocobaltate(III) and at least one further unidentified product. Given the reduced purity of this product, the solution-phase product described above was used for all diffraction measurements carried out in this study.

\subsection{Powder $X$-ray diffraction}

High-resolution synchrotron X-ray powder diffraction measurements were carried out using the I11 beamline at the Diamond Light Source. A finely-ground sample of copper(I) hexacyanocobaltate(III), prepared as above, was loaded into a borosilicate capillary $(0.5 \mathrm{~mm}$ diameter) and mounted on the diffractometer. Diffraction patterns were recorded using the Mythen2 point sensitive detector over the angular range $2 \theta=2-92^{\circ}$, using an X-ray wavelength $\lambda=0.826210 \AA$ calibrated by refinement of a silicon NIST 640c standard. Each measurement consisted of two scans of $5 \mathrm{~s}$ exposure, offset relative to one another by $\Delta 2 \theta=0.25^{\circ}$. During preliminary measurements we found the sample to be strongly sensitive to damage by the synchrotron X-ray beam. Consequently, our eventual data collection strategy involved translation of the capillary between measurements such that every measurement was carried out on a pristine sample. The sample temperature was controlled using an Oxford Cryostream (100-500 K) and a Cyberstar hot air blower (523-598 K). Diffraction patterns were measured at intervals of $25 \mathrm{~K}$ between 100 and $500 \mathrm{~K}$ and again between 523 and $598 \mathrm{~K}$. A ramp rate of $0.1 \mathrm{~K} \mathrm{~s}^{-1}$ was used between successive measurements, with an equilibration time of $60 \mathrm{~s}$ at each temperature point.

Both Pawley and Rietveld refinements were carried out using TOPAS Academic (version 4.1) [36]. We employed a modified Thompson-Cox-Hasting pseudo-Voigt (TCHZ) peak shape, combined with a simple axial divergence correction and a Stephens anisotropic peak broadening term [37]. The potassium copper(II) hexacyancobaltate(III) impurity phase was modelled using Pawley refinement of the $F m \overline{3} m$ double-metal cyanide cell $(a \sim 10 \AA)$ [38]. Rietveld refinement of the $\mathrm{Cu}_{3}\left[\mathrm{Co}(\mathrm{CN})_{6}\right]$ phase made use of a starting model based on the known structure of $\mathrm{Ag}_{3}\left[\mathrm{Co}(\mathrm{CN})_{6}\right]$ [22]. Refinement was stable for all temperature points, provided that $\mathrm{Co}-\mathrm{C} / \mathrm{C}-\mathrm{N}$ bond distance restraints and a single isotropic displacement parameter for all atom types were used in the Rietveld model. Sequential (seed-batch) Rietveld refinements, where the starting structural parameters for each temperature point were those used at the preceding temperature, provided structural models with physically-sensible temperature dependencies for $T \leq 450 \mathrm{~K}$. For the temperature regime $450 \leq T \leq 598 \mathrm{~K}$, we found that the positional coordinates of the $\mathrm{C}$ and $\mathrm{N}$ atoms and the value of $B_{\text {iso }}$ showed strong covariance, and hence we have reduced confidence in the absolute values of these parameters. This regime corresponds to the temperature range over which decomposition of the $\mathrm{KCu}\left[\mathrm{Co}(\mathrm{CN})_{6}\right]$ phase appears to set in.

\subsection{Thermal expansivity determination}

Thermal expansivities were calculated using the PASCal software 
[39]. We employed estimated temperature uncertainties of $5 \mathrm{~K}$ and fitted the principal axis expansivities using linear functions. For internal consistency with the uniaxial expansivities, the volume expansivity was determined using the trace of the expansivity tensor [40] rather than via the direct $V-T$ fit given by PASCal [39].

\subsection{Ab initio calculations}

$A b$ initio calculations were performed within the FHI-aims code [41], using the numeric atom-centred orbital tier 1 basis set for the wavefunction and a $5 \times 5 \times 5 k$-point mesh for the Brillouin zone sampling. The Perdew-Burke-Ernzerhof (PBE) functional [42] was used to model the semilocal exchange-correlation energy. To describe the non-local dispersion energies, we used both the interatomic pairwise Tkatchenko-Scheffler (TS) method [43], as well as the many-body dispersion (MBD) method, which includes many-body dipolar interatomic interactions to all orders in perturbation theory $[44,45]$. The lattice constants were obtained from unit cell relaxations with cell angles fixed to experimental values. Full a posteriori relaxation of the unit cell proved the reliability of this scheme.

\subsection{GULP calculations}

The GULP software (version 4.4) [46] was used to calculate equilibrium cell dimensions for a series of simple interaction potential models. Cell optimisations were carried out under constant pressure conditions $p=0$ and at $T=0$, with strains constrained by symmetry. Dispersion interactions were modelled using a Buckingham potential with vanishingly small repulsive term, and the 'c6' flag was activated to employ Ewald-type summation. For all calculations, checks were carried out to ensure optimisation convergence and to verify the conservation of angle terms in the parameterisation.

\section{Results and discussion}

\subsection{Crystal structure of $\mathrm{Cu}_{3}\left[\mathrm{Co}(\mathrm{CN})_{6}\right]$}

The ambient-temperature X-ray powder diffraction pattern of our $\mathrm{Cu}_{3}\left[\mathrm{Co}(\mathrm{CN})_{6}\right]$ sample is shown in Fig. 2. We could account for the entire diffraction pattern using two components, one based on the $\mathrm{Ag}_{3}\left[\mathrm{Co}(\mathrm{CN})_{6}\right]$ structure-type (space group symmetry $P \overline{3} 1 \mathrm{~m}$ ) and one with the cubic Prussian blue structure (space group symmetry $F m \overline{3} m$ ).

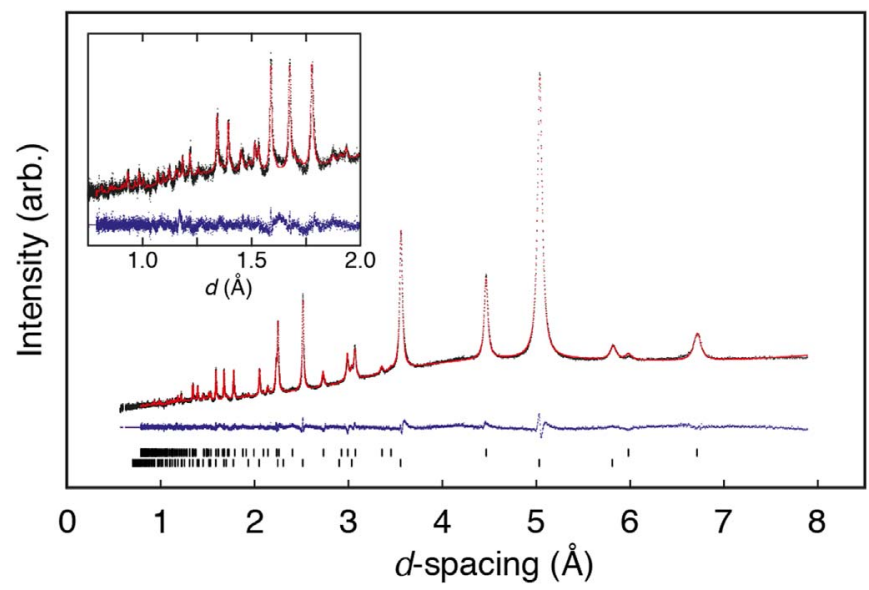

Fig. 2. X-ray powder diffraction behaviour and its interpretation in $\mathrm{Cu}_{3}\left[\mathrm{Co}(\mathrm{CN})_{6}\right]$. Experimental data are shown as black points, Rietveld fit as red points, and the difference function (data - fit) as a solid blue line. Tick marks denote the positions of symmetryallowed reflections for the $\mathrm{Cu}_{3}\left[\mathrm{Co}(\mathrm{CN})_{6}\right]$ (upper marks) and impurity $\mathrm{KCu}\left[\mathrm{Co}(\mathrm{CN})_{6}\right]$ (lower marks) phases. The inset shows a magnified representation of the fit at low-d (high-Q). (For interpretation of the references to color in this figure legend, the reader is referred to the web version of this article.)
This second phase would be consistent with the formation of $\mathrm{KCu}\left[\mathrm{Co}(\mathrm{CN})_{6}\right]$ during synthesis, which is certainly feasible on chemical grounds $[47,48]$. A Pawley fit using this two-phase model confirms our assignment of space group symmetries and rules out the presence of any additional crystalline phases. We note that there is good (if fortuitous) distinction between the diffraction profiles of the two phases present, which allows us to clearly distinguish the corresponding lattice parameters and their thermal expansion behaviour (see SI).

Having established the space group symmetry of $\mathrm{Cu}_{3}\left[\mathrm{Co}(\mathrm{CN})_{6}\right]$ we proceeded to carry out a Rietveld refinement, employing a starting model based on the lattice parameters obtained during Pawley fitting and the published atom coordinates of $\mathrm{Ag}_{3}\left[\mathrm{Co}(\mathrm{CN})_{6}\right]$ [22]. We continued to model the $\mathrm{KCu}\left[\mathrm{Co}(\mathrm{CN})_{6}\right]$ phase using a Pawley fit-indeed this is the case for all subsequent refinements and is not discussed further. We found good stability in the refinement of our structural model of $\mathrm{Cu}_{3}\left[\mathrm{Co}(\mathrm{CN})_{6}\right]$, obtaining a $R$-value of $3.029 \%$; the corresponding fit is shown in Fig. 2 and the relevant structural details are summarised in Table 1. A representation of the crystal structure itself is given in Fig. 3. All refined bond lengths are chemically sensible: we find a $\mathrm{Co}-\mathrm{C}$ distance of $1.832(11) \AA$, which is similar to that in $\mathrm{Ag}_{3}\left[\mathrm{Co}(\mathrm{CN})_{6}\right](d(\mathrm{Co}-\mathrm{C})=1.895 \AA)$ [22]; likewise the $\mathrm{Cu}-\mathrm{N}$ separation of $1.887(10) \AA$ is comparable to that found in $\mathrm{CuCN}$ $(d(\mathrm{Cu}-\mathrm{C} / \mathrm{N})=1.839(9)-1.872(12) \AA)[49]$.

A property of the particular space group symmetry of $\mathrm{Cu}_{3}\left[\mathrm{Co}(\mathrm{CN})_{6}\right]$ is that the $\mathrm{Cu}^{+} \ldots \mathrm{Cu}^{+}$separation is directly related to the lattice parameters:

$r_{\mathrm{Cu} \ldots \mathrm{Cu}}=\frac{a}{2}$.

Hence we find $r_{\mathrm{Cu} \ldots \mathrm{Cu}}=3.4543(5) \AA$, which lies at the very upper bound of $\mathrm{Cu}^{+} \ldots \mathrm{Cu}^{+}$separations for which cuprophilic interactions are considered relevant [50]. One crude measure of the strength of metallophilic interactions is to consider the ratio of the observed interatomic distance to the sum of the corresponding vdW radii [28]. Using our room-temperature lattice parameters and the vdW radii given in Ref. [51] we obtain a ratio of 1.00 for $\mathrm{Cu}_{3}\left[\mathrm{Co}(\mathrm{CN})_{6}\right]$, which is remarkably similar to the corresponding value for $\mathrm{Ag}_{3}\left[\mathrm{Co}(\mathrm{CN})_{6}\right](0.99)$ [23]. So, at face value, one might expect comparable metallophilic interaction strengths for the two systems.

\subsection{Thermal expansion behaviour}

Having collected a series of X-ray diffraction patterns over the temperature range 100-598 K, we carried out Rietveld refinements for each data set using the same approach described above. We obtained satisfactory refinements for all temperatures, albeit with some signs of increased uncertainties at the very highest temperatures-i.e., close to the onset of decomposition of the Prussian blue phase. The temperature dependence of the lattice parameters, illustrated in Fig. 4(a), was

Table 1

Structural details for $\mathrm{Cu}_{3}\left[\mathrm{Co}(\mathrm{CN})_{6}\right]$ obtained by Pawley/Rietveld refinement against Xray powder diffraction data collected at $300 \mathrm{~K}$ and estimated $0 \mathrm{~K}$ values extracted from linear fits to $100-598 \mathrm{~K}$ refinements. Atom positions are Co $(0,0,0), \mathrm{Ag}\left(\frac{1}{2}, 0, \frac{1}{2}\right), \mathrm{C}$ $\left(x_{\mathrm{C}}, 0, z_{\mathrm{C}}\right), \mathrm{N}\left(x_{\mathrm{N}}, 0, z_{\mathrm{N}}\right)$.

\begin{tabular}{lll}
\hline & $300 \mathrm{~K}$ (experimental) & $0 \mathrm{~K}$ (estimated) \\
\hline Crystal system & Trigonal & Trigonal \\
Space group & $P \overline{3} 1 m$ & $P \overline{3} 1 m$ \\
$a(\AA)$ & $6.9085(10)$ & $6.855(19)$ \\
$c(\AA)$ & $6.7077(16)$ & $6.797(19)$ \\
$V\left(\AA^{3}\right)$ & $277.25(8)$ & $276.6(17)$ \\
$x_{\mathrm{C}}$ & $0.2177(15)$ & 0.2167 \\
$z_{\mathrm{C}}$ & $0.1566(14)$ & 0.1533 \\
$x_{\mathrm{N}}$ & $0.3161(15)$ & 0.3182 \\
$z_{\mathrm{N}}$ & $0.2920(14)$ & 0.2887 \\
$B_{\text {iso }}\left(\AA^{2}\right)$ & $3.91(14)$ & - \\
\hline
\end{tabular}




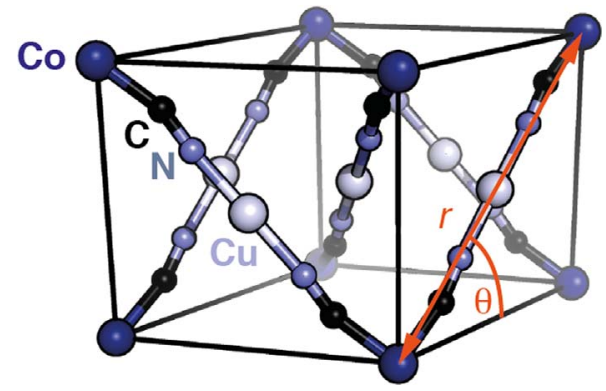

Fig. 3. Structural model for $\mathrm{Cu}_{3}\left[\mathrm{Co}(\mathrm{CN})_{6}\right]$ determined using Rietveld refinement of $\mathrm{X}$ ray powder diffraction data collected at $298 \mathrm{~K}$. Co atoms shown in dark blue, $\mathrm{Cu}$ atoms in blue-white, $\mathrm{N}$ atoms in blue, and $\mathrm{C}$ atoms in black. The XBUs $r$ and $\theta$-shown here in orange-correspond to the framework strut length and hingeing angle, respectively. (For interpretation of the references to color in this figure legend, the reader is referred to the web version of this article.)
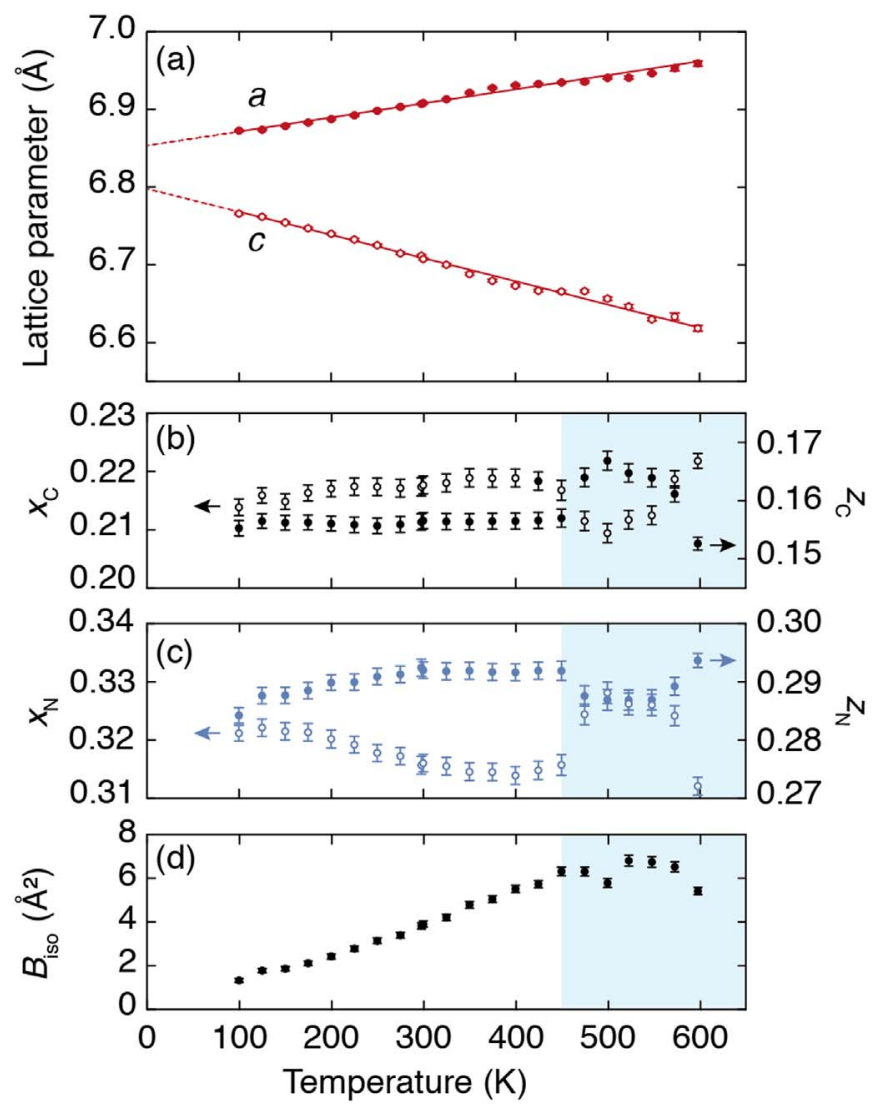

Fig. 4. Temperature dependence of structural parameters of $\mathrm{Cu}_{3}\left[\mathrm{Co}(\mathrm{CN})_{6}\right]$ as determined using variable-temperature X-ray powder diffraction. (a) Lattice parameters $a$ and $c$ (filled and open symbols, respectively), together with the linear fits (solid lines) used to determine the uniaxial coefficients of thermal expansion. The fits are extrapolated to $0 \mathrm{~K}$ (dashed lines) to give the corresponding ' $0 \mathrm{~K}$ estimates' discussed in the text. (b, c) Positional coordinates for the $\mathrm{C}$ and $\mathrm{N}$ atoms, showing smooth variation over the temperature range $100-450 \mathrm{~K}$ for which reliable Rietveld refinements were obtained. The temperature regime $450-600 \mathrm{~K}$ is shaded as refinements in this regime gave reliable lattice parameters but unreliable positional coordinates and atomic displacement parameters. (d) Isotropic atomic displacement parameter $B_{\text {iso }}=8 \pi^{2}\langle u\rangle^{2}$ used to model thermal displacements for all atoms.

observed to be approximately linear over this entire temperature range. As in nearly all members of this structural family, $\mathrm{Cu}_{3}\left[\mathrm{Co}(\mathrm{CN})_{6}\right]$ exhibits NTE effect parallel to the $c$ crystal axis, and PTE effects in perpendicular directions (i.e., including the $a$ and $b$ crystal axes). Hence the basic thermomechanical response of this system can be understood in terms of the same 'wine-rack' mechanism illustrated in Fig. 1. The remaining structural parameters $x_{\mathrm{C}}, z_{\mathrm{C}}, x_{\mathrm{N}}, z_{\mathrm{N}}, B_{\text {iso }}$ also show linear temperature dependencies [Fig. 4(b-d)]; taken together
Table 2

Experimental coefficients of thermal expansion for $A_{3}\left[\mathrm{Co}(\mathrm{CN})_{6}\right]$ systems.

\begin{tabular}{|c|c|c|c|c|c|}
\hline A & $\begin{array}{l}\alpha_{a} \\
\left(\mathrm{MK}^{-1}\right)\end{array}$ & $\begin{array}{l}\alpha_{c} \\
\left(\mathrm{MK}^{-1}\right)\end{array}$ & $\begin{array}{l}\alpha_{V} \\
\left(\mathrm{MK}^{-1}\right)\end{array}$ & $\begin{array}{l}\Delta T \\
(\mathrm{~K})\end{array}$ & Ref. \\
\hline $\mathrm{H}$ & $12.0(4)$ & $-8.8(3)$ & 15.1(6) & $4-300$ & [34] \\
\hline $\mathrm{Cu}$ & $25.4(5)$ & $-43.5(8)$ & $7.4(11)$ & $100-598$ & This work \\
\hline $\mathrm{Ag}$ & $145.9(6)$ & $-122.1(3)$ & $169.8(9)$ & $16-500$ & [23] \\
\hline
\end{tabular}

these values allow us to estimate a set of $0 \mathrm{~K}$ structural parameters that may prove useful for comparison against e.g. $a b$ initio studies [Table 1]. We note that this estimation necessarily discounts the reduction in magnitude of thermal expansion behaviour required as $T \rightarrow 0 \mathrm{~K}$ [52]. For the related systems $\mathrm{D}_{3}\left[\mathrm{Co}(\mathrm{CN})_{6}\right]$ and $\mathrm{Ag}_{3}\left[\mathrm{Co}(\mathrm{CN})_{6}\right]$, where accurate lattice parameter data exist for temperatures substantially lower than the range we are able to study here (i.e., $T \ll 20 \mathrm{~K}$ ), the error introduced by extrapolating only from data collected at $T>100 \mathrm{~K}$ is less than $0.3 \%[14,23]$. This threshold is the basis for the estimated uncertainties given for the calculated $0 \mathrm{~K}$ lattice parameters in Table 1 .

Coefficients of thermal expansion were determined using linear fits to the lattice parameter data [39], and are given in Table 2. What is immediately apparent is that the magnitudes of both PTE and NTE effects in $\mathrm{Cu}_{3}\left[\mathrm{Co}(\mathrm{CN})_{6}\right]$ are substantially smaller than those in the Agcontaining system. Consequently, $\mathrm{Cu}_{3}\left[\mathrm{Co}(\mathrm{CN})_{6}\right]$ is not a colossal thermal expansion material, and its thermomechanical response shares more in common with other $\mathrm{Cu}$-containing networks such as $\alpha-\mathrm{Cu}\left[\mathrm{C}(\mathrm{CN})_{3}\right]$ (Ref. [31]) and $\mathrm{CuCN}$ (Ref. [53]) than with $\mathrm{Ag}_{3}\left[\mathrm{Co}(\mathrm{CN})_{6}\right]$ and $\mathrm{Ag}_{3}\left[\mathrm{Fe}(\mathrm{CN})_{6}\right]$ [14]. We will come to rationalise the differences in behaviour of the copper(I) and silver(I) hexacyanocobaltates below, but include first some additional analysis of the trends in lattice parameters we observe using our newly-measured data.

The 'wine-rack' mechanism that is thermally activated in this system can be interrogated directly using the so-called mechanical building unit (XBU) approach [2]. We make use of the pair of transformations

$r=\frac{1}{2} \sqrt{a^{2}+c^{2}}$,

$\theta=\tan ^{-1}\left(\frac{c}{a}\right)$,

which relate the unit cell dimensions to the framework strut length $r$ and framework angle $\theta$ [Fig. 3]. Using these same relationships, we can recast the lattice expansivities in terms of XBU expansivities, obtaining $\alpha_{r}=-8.2 \mathrm{MK}^{-1}$ and $\alpha_{\theta}=43.1 \mathrm{MK}^{-1}$. Hence the bulk of the thermal expansion response can be accounted for by changes in the framework geometry $\left(\left|\alpha_{\theta}\right| \gg\left|\alpha_{r}\right|\right)$; the lattice expansivities attributable to this flexing mechanism alone are $\alpha_{a}{ }^{\prime}=33.5 \mathrm{MK}^{-1}$ and $\alpha_{c}{ }^{\prime}=-35.7 \mathrm{MK}^{-1}$, where we use the prime notation to indicate calculation from $\alpha_{\theta}$. The observation $\alpha_{r}<0$ indicates that the $\mathrm{Co}-\mathrm{CN}-\mathrm{Cu}-\mathrm{NC}-\mathrm{Co}$ 'struts' from which the framework structure of $\mathrm{Cu}_{3}\left[\mathrm{Co}(\mathrm{CN})_{6}\right]$ is assembled actually contract with increasing temperature. This behaviour is likely due to thermal activation of transverse vibrational modes where lateral displacements of the chain (maximal at the $\mathrm{Cu}$ site) require shortening of the Co...Co vector $[52,54]$. Such a mechanism is implicated in the uniaxial NTE of CuCN itself ( $\alpha_{\text {chain }}=-32.1 \mathrm{MK}^{-1}$, Ref. [49,53]), and is presumably tempered here somewhat relative to that system by the increased strength of $\mathrm{Co}^{\mathrm{III}}-\mathrm{C}$ vs $\mathrm{Cu}^{\mathrm{I}}-\mathrm{C}$ bonds [47].

One consequence of the negative value of $\alpha_{r}$ is that the volume coefficient of thermal expansion of $\mathrm{Cu}_{3}\left[\mathrm{Co}(\mathrm{CN})_{6}\right]$ is unusually small for systems in this particular family. Formally, this situation arises because of the fortuitous equivalence $\alpha_{r} \simeq-\frac{1}{3}\left|\alpha^{\prime}\right|$, which is the geometric requirement for $\alpha_{V} \rightarrow 0 .{ }^{1}$ Hence this material has the unusual property

\footnotetext{
${ }^{1}$ Note that $\alpha_{i}=\alpha_{i}{ }^{\prime}+\alpha_{r}$, and hence $\alpha_{V} \sim \alpha_{a}{ }^{\prime}+3 \alpha_{r}$
} 
of (approximately) temperature-independent density despite its relatively large linear thermal expansivities. At face value, this property may be expected to result in unusually extreme uniaxial compressibilities under application of hydrostatic pressure, since small changes in volume would appear to be linked to large changes in lattice dimensions. However, we anticipate by analogy to related systems that the XBU compressibility $K_{r}$ is actually positive rather than negative, and so a small $\alpha_{V}$ need not require a large bulk modulus [2,55]. Nevertheless we expect the particular uniaxial compressibility corresponding to the $c$ crystal axis to be negative, and so investigation of the NLC behaviour of $\mathrm{Cu}_{3}\left[\mathrm{Co}(\mathrm{CN})_{6}\right]$ could prove a fruitful avenue of future research.

\subsection{Ab initio calculations}

The observation of more moderate thermal expansion behaviour in $\mathrm{Cu}_{3}\left[\mathrm{Co}(\mathrm{CN})_{6}\right]$ relative to that in $\mathrm{Ag}_{3}\left[\mathrm{Co}(\mathrm{CN})_{6}\right]$ poses a simple question: does this situation arise because cuprophilic interactions are actually stronger than argentophilic interactions, and hence less susceptible to changes in temperature?

In order to answer this question, we turn to $a b$ initio calculations, which if carried out so as to include consideration of vdW interactions allow direct quantification of the metallophilic interactions in both compounds. We begin by reporting the $0 \mathrm{~K}$ structure for $\mathrm{Cu}_{3}\left[\mathrm{Co}(\mathrm{CN})_{6}\right]$ obtained computationally and demonstrate that the inclusion of dispersive interactions is necessary to improve consistency with our experimental results. By mapping out the potential energy surface (PES) for all three $\mathrm{A}_{3}\left[\mathrm{Co}(\mathrm{CN})_{6}\right]$ systems $(\mathrm{A}=\mathrm{H}, \mathrm{Cu}, \mathrm{Ag})$ across a variety of lattice strains and then taking into account the variation in vdW energies at each point, we extract the free-atom and in-solid (effective) $C_{6}$ coefficients. The value of these coefficients for each atom type A acts as a measure of the strength of metallophilic interactions in the corresponding $\mathrm{A}_{3}\left[\mathrm{Co}(\mathrm{CN})_{6}\right]$ system.

The unit cell dimensions obtained in our DFT $+\mathrm{vdW}$ calculations are given in Table 3. The influence of dispersion energy on the lattice constants is large, just as is now known to be the case for $\mathrm{Ag}_{3}\left[\mathrm{Co}(\mathrm{CN})_{6}\right]$ [56]. Our PBE calculation without vdW interactions overestimates $a$ and underestimates $c$. Upon including dispersion interactions the lattice constants move closer to the experimental values. We note that the enhanced cohesive MBD energy for $\mathrm{Cu}_{3}\left[\mathrm{Co}(\mathrm{CN})_{6}\right]$ arises from the collective effect of vdW interactions and the self-consistent polarisation in the unit cell [56]. The agreement with experiment is somewhat less exact than for $\mathrm{Ag}_{3}\left[\mathrm{Co}(\mathrm{CN})_{6}\right]$ [56]; possible reasons include (i) the approximations implicit in extrapolating our $T>100 \mathrm{~K}$ experimental data to $0 \mathrm{~K}$, (ii) the need for a higher-level hybrid DFT base functional, and (iii) the sensitivity of the dispersion energy at short interatomic distances to the parameterisation of the damping function.

In Fig. 5 we show a representative section of the PES for the three calculation regimes, and Fig. 6 shows the TS and MBD vdW energies as a function of the individual $a$ and $c$ lattice constants. Our results make clear that the vdW energy depends more strongly on $a$ than it does on $c$.
Table 3

Comparison between experimental and $a b$ initio lattice parameters for $\mathrm{Cu}\left[\mathrm{Co}(\mathrm{CN})_{6}\right]$. The difference term $\Delta$ corresponds to the sum of absolute cell strains $\sum_{i}\left|\left(x_{i, \text { calc }}-x_{i, \exp }\right) / x_{i, \exp }\right|$.

\begin{tabular}{lllll}
\hline & exp. $(0 \mathrm{~K})$ & PBE & TS & MBD \\
\hline$a(\AA)$ & 6.855 & 7.267 & 7.130 & 6.495 \\
$c(\AA)$ & 6.797 & 6.365 & 6.432 & 6.978 \\
$V\left(\AA^{3}\right)$ & 276.6 & 291.06 & 283.00 & 254.98 \\
$\Delta(\%)$ & 0 & 18.4 & 13.4 & 13.2 \\
\hline
\end{tabular}

Since the framework strut length $r$ is more rigid than the framework angle $\theta$, then to lower the total energy the lattice simply contracts along $a$ (and $b$ ) while expanding along $c$. Hence the same mechanism explains the qualitative change in lattice constants observed both as a result of using different vdW calculation methods and as a result of an increase in the polarisability of atom A. Indeed because the MBD energy depends almost linearly on the lattice constants it behaves as an effective pressure on the lattice, equivalent to $1.22 \mathrm{GPa}$ along $a$ and $1.76 \mathrm{GPa}$ along $c$.

To compare the strength of cuprophilic interactions in $\mathrm{Cu}_{3}\left[\mathrm{Co}(\mathrm{CN})_{6}\right]$ with that of argentophilic interactions in $\mathrm{Ag}_{3}\left[\mathrm{Co}(\mathrm{CN})_{6}\right]$ we further analysed our DFT + vdW results. Our basic approach was to parameterise the vdW contribution to the TS-vdW energy in terms of dispersion coefficients $C_{6}$ and vdW radii $R_{0}$ for each atom type. In the $\mathrm{PBE}+\mathrm{TS}$ calculations, the free-atom $C_{6}$ coefficient and vdW radii $R_{0}$ are used as the initial input parameters. The effect of the local chemical environment is taken into account by calculating the effective in-solid $C_{6}$ and $R_{0}$ as described in Ref. [43]. Table 4 lists our results for the freeatom vdW parameters and the effective parameters for $\mathrm{A}_{3}\left[\mathrm{Co}(\mathrm{CN})_{6}\right]$ (A $=\mathrm{Ag}, \mathrm{Cu}, \mathrm{H})$ at the experimental lattice constants. We find that the argentophilic interactions are indeed stronger than cuprophilic interactions in these systems, as both the free-atom and effective $C_{6}$ values are larger by $\sim 40 \%$ for $\mathrm{Ag}$ relative to $\mathrm{Cu}$. For completeness we note that the effect of the local chemical environment on the $C_{6}$ coefficients is to reduce the dispersion coefficients.

\subsection{GULP calculations}

We supplement these high-level $a b$ initio results with a series of extremely simple model calculations that also allow us to estimate the relative strengths of metallophilic interactions in $\mathrm{Cu}_{3}\left[\mathrm{Co}(\mathrm{CN})_{6}\right]$ and $\mathrm{Ag}_{3}\left[\mathrm{Co}(\mathrm{CN})_{6}\right]$. The approach we use is to develop the very simplest abstraction of all three $\mathrm{A}_{3}\left[\mathrm{Co}(\mathrm{CN})_{6}\right]$ systems $(\mathrm{A}=\mathrm{H}, \mathrm{Cu}, \mathrm{Ag})$ that captures the key interactions responsible for their thermomechanical response. We parameterise this model with sufficiently few variables that six experimental observables (the two independent lattice parameters for each of the three systems) can be used to estimate metallophilic interaction strengths in the $\mathrm{A}=\mathrm{Cu}, \mathrm{Ag}$ compounds.

The same structural model is used for all three systems: $P \overline{3} 1 \mathrm{~m}$ crystal symmetry, with a single anion (mass $m=m\left(\mathrm{CoC}_{6} \mathrm{~N}_{6}\right)$ ) of charge $-1.5 e$ at position $(0,0,0)$ and a cation $(m=m(\mathrm{~A}))$ with charge $+0.5 e$ at
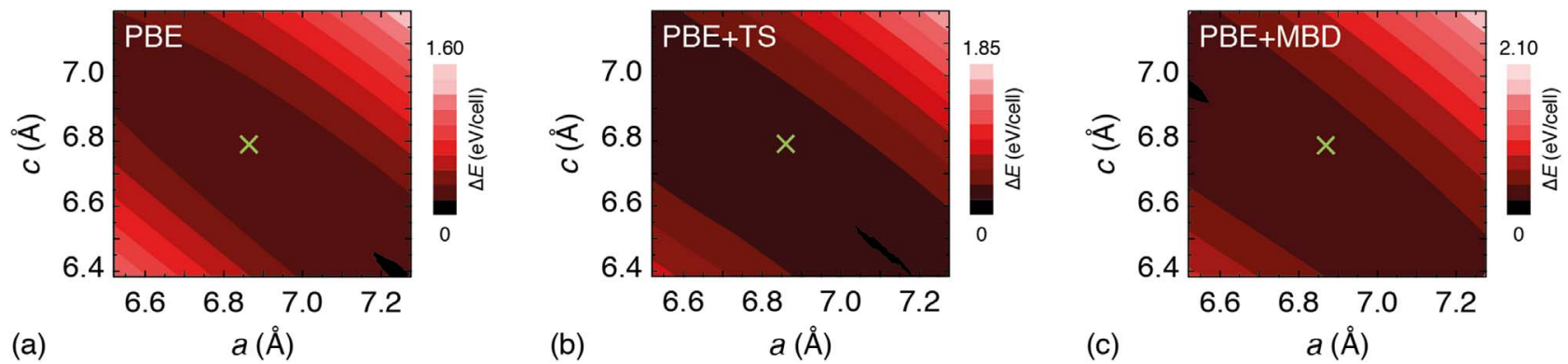

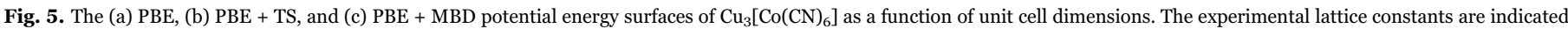
by crosses. Energies are given relative to the ground state in each case. 


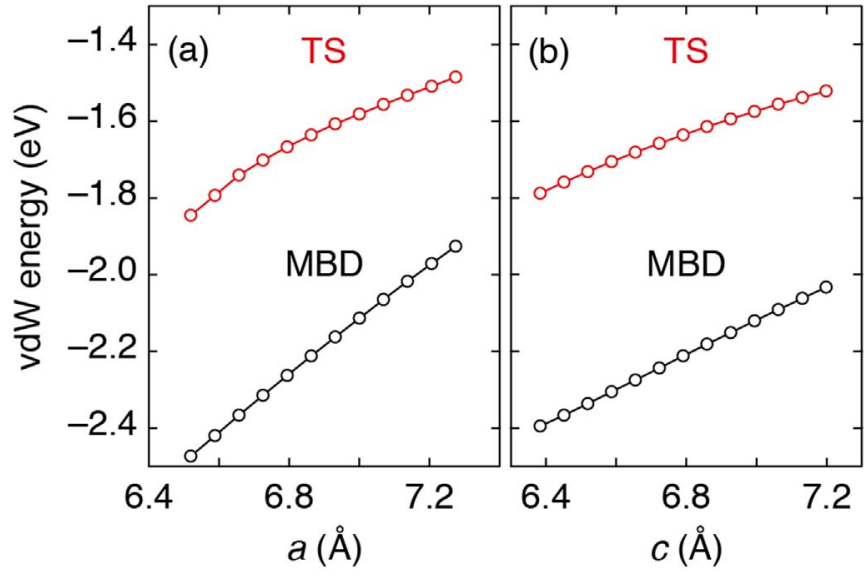

Fig. 6. The TS and MBD vdW energies in $\mathrm{Cu}_{3}\left[\mathrm{Co}(\mathrm{CN})_{6}\right]$ per unit cell (a) as a function of lattice constant $a$ with $c$ fixed to experimental values and (b) as a function of $c$ with $a$ fixed to experimental values.

Table 4

The PBE + TS free-atom and in-solid vdW parameters for A atoms in $\mathrm{A}_{3}\left[\mathrm{Co}(\mathrm{CN})_{6}\right](\mathrm{A}=$ $\mathrm{Ag}, \mathrm{Cu}, \mathrm{H})$ at experimental lattice constants.

\begin{tabular}{llllll}
\hline & \multicolumn{2}{l}{$C_{6}\left(\right.$ hartree bohr $\left.{ }^{6}\right)$} & & \multicolumn{2}{l}{$R_{0}$ (bohr) } \\
\cline { 2 - 3 } \cline { 5 - 6 } & free-atom & in-solid & & free-atom & in-solid \\
\hline $\mathrm{Ag}_{3}\left[\mathrm{Co}(\mathrm{CN})_{6}\right]$ & 339.00 & 295.73 & & 3.82 & 3.73 \\
$\mathrm{Cu}_{3}\left[\mathrm{Co}(\mathrm{CN})_{6}\right]$ & 235.00 & 207.03 & & 3.76 & 3.64 \\
$\mathrm{H}_{3}\left[\mathrm{Co}(\mathrm{CN})_{6}\right]$ & 6.50 & 4.28 & & 3.10 & 2.89 \\
\hline
\end{tabular}

position $\left(\frac{1}{2}, 0, \frac{1}{2}\right)$ [Fig. $7($ a) $]$. These charges reflect the approximate Mulliken charges determined for $\mathrm{H}_{3}\left[\mathrm{Co}(\mathrm{CN})_{6}\right]$ and $\mathrm{Ag}_{3}\left[\mathrm{Co}(\mathrm{CN})_{6}\right]$ in Ref. [57] and are consistent with the Hirshfeld and Bader charges obtained in our own $a b$ initio calculations (see SI). We refer to the anion using the symbol $\mathrm{X}$ (formally this corresponds to the $\left[\mathrm{Co}(\mathrm{CN})_{6}\right]^{3-}$ ion), giving the unit cell composition $\mathrm{A}_{3} \mathrm{X}$. This structural model is then decorated with three interaction potentials: first, a harmonic bond potential between neighbouring $\mathrm{A}$ and $\mathrm{X}$ sites with force-constant $k_{r}$; second, a harmonic bond-angle potential governing $\mathrm{A}-\mathrm{X}-\mathrm{A}$ triplets with force-constant $k_{\theta}$; and, third, (in the case of $\mathrm{Cu}$ and $\mathrm{Ag}$ systems) dispersive interactions between neighbouring A sites intended to reflect the empirical $\frac{1}{r^{6}}$-dependence of metallophilic interactions [58]. The prefactor $C_{6}$ of this dispersive term quantifies the strength of metallophilic interactions.

In order to reduce the number of parameters involved in this model, we make the following assumptions. First, we take the effective charges at $\mathrm{X}$ and $\mathrm{A}$ sites to be system-independent. We justify this assumption by noting that the Mulliken charges reported for $\mathrm{H}_{3}\left[\mathrm{Co}(\mathrm{CN})_{6}\right]$ and $\mathrm{Ag}_{3}\left[\mathrm{Co}(\mathrm{CN})_{6}\right]$ vary more greatly by calculation method than they do between systems [57]; the $\mathrm{A}=\mathrm{Cu}$ case is intermediate to the $\mathrm{A}=\mathrm{H}$ and $\mathrm{A}=\mathrm{Ag}$ cases (see $\mathrm{SI}$ ). Second, we take the flexing stiffness $k_{\theta}$ and equilibrium angle $\theta_{0}$ also to be systemindependent, with $\theta_{0}$ as close to $90^{\circ}$ as possible. This is probably reasonable given that both terms will be governed by the chemistry of the $\left[\mathrm{Co}(\mathrm{CN})_{6}\right]^{3-}$ anion, which is common to all three systems. Third, we take the (system-dependent) values of $r_{0}$ as the sum of bond lengths $d(\mathrm{Co}-\mathrm{C})+d(\mathrm{C}-\mathrm{N})+d(\mathrm{~N}-\mathrm{A})$ determined crystallographically: we use the values from Ref. [34] for $\mathrm{A}=\mathrm{H}$, from Ref. [17] for $\mathrm{A}=\mathrm{Ag}$, and from our present study for $\mathrm{A}=\mathrm{Cu}$.

We proceeded to determine a set of parameters $k_{r}, k_{\theta}, \theta_{0}$ that, when used to drive geometry optimisation, result in the closest possible agreement between $0 \mathrm{~K}$ (derived from experiment) and relaxed cell parameters for $\mathrm{A}=\mathrm{H}$. Our results are listed in Table 5, together with a comparison of the experimental and simulated lattice parameters; the corresponding match in framework geometry is illustrated in Fig. $7 .^{2}$ We note that we do not attach any particular physical meaning to the parameter values in our model, since (in particular) the charge distribution we use is heavily simplified. Nevertheless it is reassuring that even this simple model allows robust geometry optimisation to a physically-sensible state.

Having used the geometry of the $\mathrm{A}=\mathrm{H}$ system to determine all of the system-independent parameter values, we proceeded to optimise the geometry of analogous models for $\mathrm{A}=\mathrm{Cu}$ and $\mathrm{Ag}$. In each case the value of $r_{0}$ was updated according to the experimental bond lengths, and only the value of $C_{6}$ was varied in order to obtain the closest match between calculated and experimental ( $0 \mathrm{~K}$ extrapolated) lattice parameters. The corresponding parameter values and optimised cell dimensions are again summarised in Table 5; we note that the level of agreement $(<2 \%$ ) is encouraging given the simplicity of the GULP model we have used. Also encouraging is that, for both compounds, the $a$ lattice parameters are overestimated in the absence of a metallophilic contribution to the lattice enthalpy. This indicates that the electrostatic contribution to the free energy (the single component of our model acting to increase $a$ ) operates in tension with the metallophilic interactions. While we do not attach any importance to the absolute values of the $C_{6}$ parameters that emerge from our calculations, what we do think is meaningful is the observation that $C_{6}$ is larger for $\mathrm{A}=\mathrm{Ag}$ than for $\mathrm{A}=\mathrm{Cu}$. In other words, the experimental unit cell dimensions for $\mathrm{Cu}_{3}\left[\mathrm{Co}(\mathrm{CN})_{6}\right]$ and $\mathrm{Ag}_{3}\left[\mathrm{Co}(\mathrm{CN})_{6}\right]$ are consistent with stronger argentophilic interactions in the latter than cuprophilic interactions in the former. Moreover, the ratio of cuprophilic:argentophilic interaction strengths we deduce from our simple GULP model is essentially the same as that obtained in our $a b$ initio calculations: $C_{6}(\mathrm{Cu}) / C_{6}(\mathrm{Ag})=61 \%$ vs $70 \%$, respectively.

\subsection{Flexibility from competing interactions}

So our various calculations converge on the same scenario whereby cuprophilic interactions in $\mathrm{Cu}_{3}\left[\mathrm{Co}(\mathrm{CN})_{6}\right]$ are weaker than argentophilic interactions in $\mathrm{Ag}_{3}\left[\mathrm{Co}(\mathrm{CN})_{6}\right]$ by $30-40 \%$. One obvious question remains: how is this observation consistent with the more moderate thermal expansion behaviour of the $\mathrm{Cu}$-containing compound?

To address this question we exploit the approximate proportionality between thermal expansivities and isothermal compressibilities noted in Refs. [17,27,59]:

$\alpha_{i} \simeq \frac{C_{T}}{V} \hat{\gamma} K_{i}$.

Here $C_{T}$ is the isothermal specific heat, $V$ the molar volume, $\hat{\gamma}$ the mean effective Grüneisen parameter and $K_{i}$ the uniaxial compressibilities. We estimate that the pre-factor $C_{T} \hat{\gamma} / V$ varies by not more than $\sim 25 \%$ between the $\mathrm{A}=\mathrm{Cu}$ and $\mathrm{A}=\mathrm{Ag}$ systems, ${ }^{3}$ such that a comparison of compressibilities for the two compounds provides a reasonable firstorder approximation to the relative thermal expansivities. We concern ourselves with compressibilities rather than expansivities since the former are obtainable directly from the calculations (both $a b$ initio and GULP) described above. The relative compressibilities for all three compounds are illustrated graphically in Fig. 8 . What is evident is that the $\mathrm{Cu}$-containing compound exhibits intermediate behaviour to the $\mathrm{H}$ and Ag-containing systems, despite its relatively weaker metallophilic

\footnotetext{
${ }^{2}$ We found the quality of fit was relatively insensitive to changes in $k_{r}$ of up to $c a 25 \%$ of its value. Variations in this parameter did affect the absolute values of the compressibilities determined subsequently; however the same trend in magnitudes of compressibilities shown in Fig. 8 was found in all cases.

${ }^{3}$ Here we have made use of three relationships: first, that $\hat{\gamma}$ appears to be relatively system-independent [57]; second, that the ratio of the $C_{T}$ values for $\mathrm{A}=\mathrm{Cu}$ and $\mathrm{Ag}$ will be approximately equal to the ratio of the $\sqrt{m}$ terms, since the low-energy phonon dispersion will be dominated by heavy-atom displacements; and third, we use the experimental molar volumes.
} 

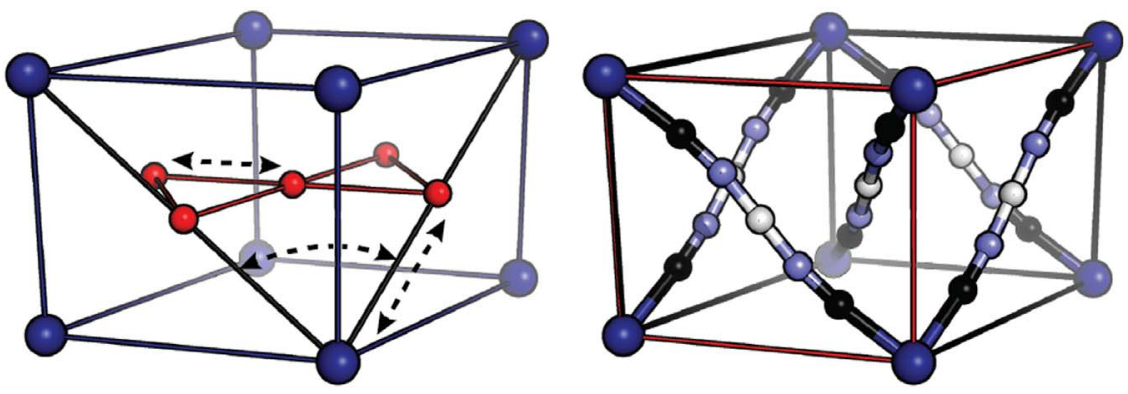

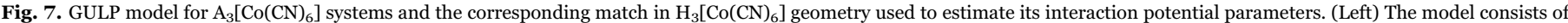

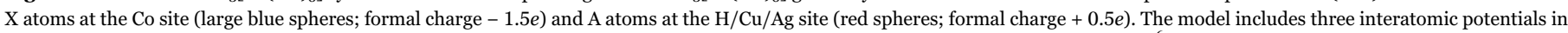

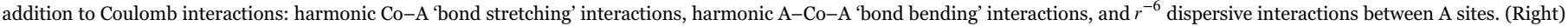

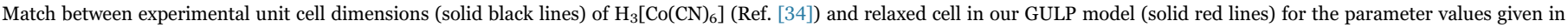
Table 5. (For interpretation of the references to color in this figure legend, the reader is referred to the web version of this article.)

Table 5

GULP model parameters and comparison between calculated and observed lattice parameters. Refined parameters are shown in bold.

\begin{tabular}{llll}
\hline & $\mathrm{H}_{3}\left[\mathrm{Co}(\mathrm{CN})_{6}\right]$ & $\mathrm{Cu}_{3}\left[\mathrm{Co}(\mathrm{CN})_{6}\right]$ & $\operatorname{Ag}_{3}\left[\mathrm{Co}(\mathrm{CN})_{6}\right]$ \\
\hline$k_{r}\left(\mathrm{eV} / \AA^{2}\right)$ & $\mathbf{4 0 0}$ & 400 & 400 \\
$r_{0}(\AA)$ & 4.319 & 4.867 & 5.070 \\
$k_{\theta}\left(\mathrm{eV} / \mathrm{rad}^{2}\right)$ & $\mathbf{4 7}$ & 47 & 47 \\
$\theta_{0}\left({ }^{\circ}\right)$ & $\mathbf{8 9}$ & 89 & 89 \\
$C_{6}\left(\mathrm{eV} \AA^{6}\right)$ & 0 & $\mathbf{8 8 1 0}$ & $\mathbf{1 4 , 4 0 0}$ \\
& & & \\
$a(\AA)$ & 6.450 & 6.901 & 6.812 \\
$a_{\text {expt }}^{0} \mathrm{~K}(\AA)$ & 6.409 & 6.855 & 6.740 \\
$\Delta a / a(\%)$ & $+0.6 \%$ & $+0.7 \%$ & $+1.1 \%$ \\
$c(\AA)$ & 5.749 & 6.842 & 7.474 \\
$c_{\text {expt }}^{0} \mathrm{~K}(\AA)$ & 5.713 & 6.797 & 7.390 \\
$\Delta c / c(\%)$ & $+0.6 \%$ & $+0.7 \%$ & $+1.1 \%$ \\
\hline
\end{tabular}

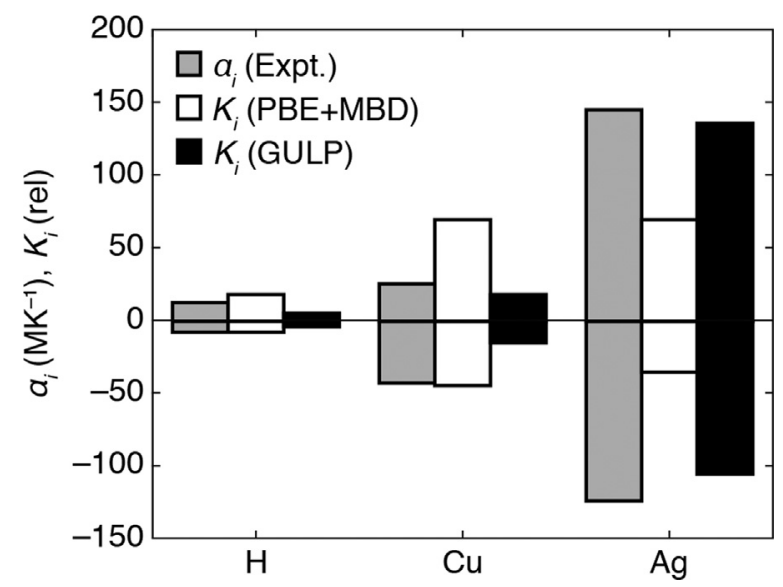

Fig. 8. Trends in calculated uniaxial compressibilities (white bars = ab initio; black bars = GULP; data normalised for comparison) and lattice expansivities (grey bars = values taken from Refs. $[23,34]$ and this study) for $\mathrm{A}_{3}\left[\mathrm{Co}(\mathrm{CN})_{6}\right]$ compounds.

interactions. The qualitative similarity to the relative thermal expansivities is striking, particularly given the (necessary) omission of anharmonic contributions from our calculations which likely contribute substantially to the experimental behaviour [60].

\section{Concluding remarks}

We are led to the counterintuitive conclusion that stronger interactions can actually make a material more compliant: $\mathrm{Ag}_{3}\left[\mathrm{Co}(\mathrm{CN})_{6}\right]$ exhibits colossal thermomechanical responses but $\mathrm{Cu}_{3}\left[\mathrm{Co}(\mathrm{CN})_{6}\right]$ does not, despite the energy scale associated with metallophilic interactions being larger in the former than in the latter. Of course the key here is that metallophilic interactions are net attractive, and act in tension with the (repulsive) electrostatic component $[61,62]$. Any effective harmonic potential can be made increasingly shallow by the addition of attractive $r^{-6}$ terms, as illustrated in Fig. 9. This is the nub of the physics at play in this family: in the absence of metallophilic interactions, the frameworks are not especially mechanically responsive but they do become so as metallophilicity is introduced.

Hence the conventional materials design rules are reversed, and we anticipate that the member of the $\mathrm{A}_{3}\left[\mathrm{Co}(\mathrm{CN})_{6}\right]$ family likely to show the most extreme thermomechanical response is actually the as-yetunrealised compound $\mathrm{Au}_{3}\left[\mathrm{Co}(\mathrm{CN})_{6}\right]$. It was shown in Ref. [57] that this system is likely to have a particularly compliant structure, although the degree of compliance will depend heavily on the strength of the aurophilic interaction contribution to the lattice enthalpy. Given the notorious difficulty of accessing aqueous $\mathrm{Au}(\mathrm{I})$ chemistry, it is not yet clear how $\mathrm{Au}_{3}\left[\mathrm{Co}(\mathrm{CN})_{6}\right]$ might be accessed synthetically. A viable alternative is the (also unrealised) compound $\mathrm{Fe}\left[\mathrm{Au}(\mathrm{CN})_{2}\right]_{3}-$ i.e., with $\mathrm{Co}(\mathrm{III})$ replaced by $\mathrm{Fe}(\mathrm{III})$ and the $\mathrm{CN}$ ion orientations reversedwhich by analogy to $\mathrm{Fe}\left[\mathrm{Ag}(\mathrm{CN})_{2}\right]_{3}$ should in principle be accessible via reaction of aqueous $\mathrm{Fe}^{3+}$ containing solutions with $\mathrm{KAu}(\mathrm{CN})_{2}$ [63]. The observation [14] of qualitatively similar 'colossal' thermal expansion in $\mathrm{Ag}_{3}\left[\mathrm{Co}(\mathrm{CN})_{6}\right]$ and $\mathrm{Ag}_{3}\left[\mathrm{Fe}(\mathrm{CN})_{6}\right]$ suggests that chemical substitution at the trivalent metal site is unlikely to influence the degree of thermomechanical response observed.

With respect to $\mathrm{Cu}_{3}\left[\mathrm{Co}(\mathrm{CN})_{6}\right]$, further spectroscopic and lattice dynamical studies will likely prove valuable in understanding more deeply the microscopic origin of its NTE response, as has been the case for the other materials in this family $[64,65]$. While it has not been computationally feasible in our study to extend the MBD calculations to finite temperatures, a clear computational challenge for future investigations is the calculation of the phonon dispersion relation and thermal expansivity tensor of $\mathrm{Cu}_{3}\left[\mathrm{Co}(\mathrm{CN})_{6}\right]$, including MBD effects.

From a computational perspective, one key implication of our study is the importance of obtaining accurate descriptions of vdW interactions in compliant framework materials. This importance is particularly

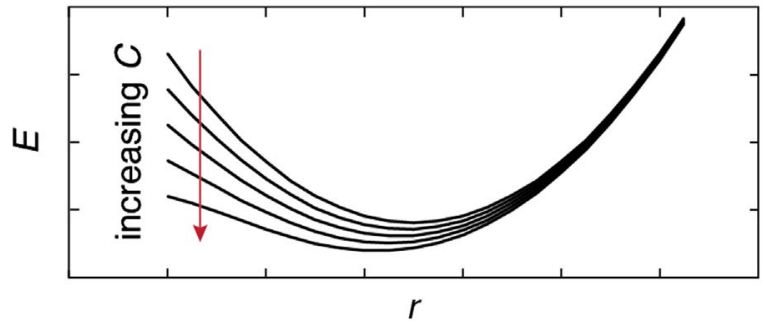

Fig. 9. Flattening of an effective interaction potential $E=\frac{1}{2} k\left(r-r_{0}\right)^{2}+C_{6} r^{-6}$ with increasing dispersion interaction strength $C_{6}$. Reduced curvature leads to more extreme expansivity and compressibility behaviour. 
acute for systems such as $\mathrm{Cu}_{3}\left[\mathrm{Co}(\mathrm{CN})_{6}\right]$ and $\mathrm{Ag}_{3}\left[\mathrm{Co}(\mathrm{CN})_{6}\right]$ where the PES is anomalously shallow as a result of competition between vdW and electrostatic contributions. As flagged above, a key challenge in this regard is the treatment of finite-temperature effects; i.e. anharmonicity. We anticipate that the discovery of anomalous mechanics in increasingly many systems based on vdW-type interactions $[66,67]$ will motivate further research effort along precisely these lines.

\section{Acknowledgements}

The synchrotron diffraction measurements were carried out at the Diamond Light Source (I11 Beamline). We are extremely grateful for the award of a Block Allocation Grant, which made this work possible, and for the assistance in data collection provided by S.J. Cassidy (Oxford) and the I11 beamline staff. A.F.S., A.R.O. and A.L.G. gratefully acknowledge funding through the European Research Council (Grant 279705). C.S.C. and A.L.G. acknowledge funding through the Leverhulme Trust (Grant RPG-2015-292). A.R.O. thanks the Diamond Light Source for a Studentship. This project received funding from the European Union (EU) Horizon 2020 Research and Innovation Programme under Marie Sklodowska-Curie Grant Agreement 641887 (project acronym DEFNET).

\section{Appendix A. Supplementary data}

Supplementary data associated with this article can be found in the online version at http://dx.doi.org/10.1016/j.jssc.2017.10.009.

\section{References}

[1] F.-X. Coudert, Responive metal-organic frameworks and framework materials: under pressure, taking the heat, in the spotlight, with friends, Chem. Mater. 27 (2015) 1905-1916.

[2] J.M. Ogborn, I.E. Collings, S.A. Moggach, A.L. Thompson, A.L. Goodwin, Supramolecular mechanics in a metal-organic framework, Chem. Sci. 3 (2012) 3011-3017.

[3] S. Horike, S. Shimomura, S. Kitagawa, Soft porous crystals, Nat. Chem. 1 (2009) 695-704.

[4] G.R. Krishna, R. Devarapalli, G. Lal, C.M. Reddy, Mechanically flexible organic crystals achieved by introducing weak interactions in structure: supramolecular shape synthons, J. Am. Chem. Soc. 138 (2016) 13561-13567.

[5] D. Das, T. Jacobs, L.J. Barbour, Exceptionally large positive and negative anisotropic thermal expansion of an organic crystalline material, Nat. Mater. 9 (2010) 36-39.

[6] A.L. Goodwin, Organic crystals: packing down, Nat. Mater. 9 (2010) 7-8.

[7] H.J. Shepherd, T. Palamarciuc, P. Rosa, P. Guionneau, G. Molnár, J.-F. Létard, A. Bousseksou, Antagonism between extreme negative linear compressibility and spin crossover in $\left[\mathrm{Fe}(\mathrm{dpp})_{2}(\mathrm{NCS})_{2}\right] \cdot$ py, Angew. Chem. Int. Ed. 51 (2012) 3910-3914.

[8] S.G. Duyker, V.K. Peterson, G.J. Kearley, A.J. Studer, C.J. Kepert, Extreme compressibility in $\mathrm{LnFe}(\mathrm{CN})_{6}$ coordination framework materials via molecular gears and torsion springs, Nat. Chem. 8 (2016) 270-275.

[9] W. Li, A. Thirumurugan, P.T. Barton, Z. Lin, S. Henke, H.H.-M. Yeung, M.T. Wharmby, E.G. Bithell, C.J. Howard, A.K. Cheetham, Mechanical tunability via hydrogen bonding in metal-organic frameworks with the perovskite architecture, J. Am. Chem. Soc. 136 (2014) 7801-7804.

[10] R.H. Jones, K.S. Knight, W.G. Marshall, J. Clews, R.J. Darton, D. Pyatt, S.J. Coles, P.N. Horton, Colossal thermal expansion and negative thermal expansion in simple halogen bonded complexes, CrystEngComm 16 (2014) 237-243.

[11] P.G. Yot, Q. Ma, J. Haines, Q. Yang, A. Ghoufi, T. Devic, C. Serre, V. Dmitriev, G. Férey, C. Zhong, G. Maurin, Large breathing of the MOF MIL-47(V $\left.{ }^{\mathrm{IV}}\right)$ under mechanical pressure: a joint experimental-modelling exploration, Chem. Sci. 3 (2012) 1100-1104.

[12] E.R. Engel, V.J. Smith, C.X. Bezuidenhout, L.J. Barbour, Uniaxial negative thermal expansion facilitated by weak host-guest interactions, Chem. Commun. 50 (2014) 4238-4241.

[13] F. Salles, G. Maurin, C. Serre, P.L. Llewellyn, C. Knöfel, H.J. Choi, Y. Filinchuk, L. Oliviero, A. Vimont, J.R. Long, G. Férey, Multistep, $\mathrm{N}_{2}$ breathing in the metalorganic framework Co(1,4-benzenedipyrazolate), J. Am. Chem. Soc. 132 (2010) 13782-13788.

[14] A.L. Goodwin, D.A. Keen, M.G. Tucker, M.T. Dove, L. Peters, J.S.O. Evans, Argentophilicity-dependent colossal thermal expansion in extended Prussian Blue analogues, J. Am. Chem. Soc. 130 (2008) 9660-9661.

[15] C.Y. Ho, R.E. Taylor, Thermal Expansion of Solids, ASM International, Ohio, 1998.

[16] R. Krishnan (Ed.)Thermal Expansion of Crystals, Vol. 22 of International Series on the Science of the Solid State, Pergamon Press, Oxford, 1979.
[17] A.L. Goodwin, D.A. Keen, M.G. Tucker, Large negative linear compressibility of $\mathrm{Ag}_{3}\left[\mathrm{Co}(\mathrm{CN})_{6}\right]$, Proc. Natl. Acad. Sci. USA 105 (2008) 18708-18713.

[18] G.N. Greaves, A.L. Greer, R.S. Lakes, T. Rouxel, Poisson's ratio and modern materials, Nat. Mater. 10 (2011) 823-837.

[19] M.K. Panda, T. Runčevski, S. Chandra Sahoo, A.A. Belik, N.K. Nath, R.E. Dinnebier, P. Naumov, Colossal positive and negative thermal expansion and thermosalient effect in a pentamorphic organometallic martensite, Nat. Commun. 5 (2014) 4811.

[20] M.K. Panda, R. Centore, M. Causà, A. Tuzi, F. Borbone, P. Naumov, Strong and anomalous thermal expansion precedes the thermosalient effect in dynamic molecular crystals, Sci. Rep. 6 (2016) 29610.

[21] J.L. Korčok, M.J. Katz, D.B. Leznoff, Impact of metallophilicity on "colossal" positive and negative thermal expansion in a series of isostructural dicyanometallate coordination polymers, J. Am. Chem. Soc. 131 (2009) 4866-4871.

[22] A. Ludi, H.U. Güdel, Die Kristallstruktur von $\mathrm{Ag}_{3} \mathrm{Co}(\mathrm{CN})_{6}$, Helv. Chim. Acta 51 (1968) 1762-1765.

[23] A.L. Goodwin, M. Calleja, M.J. Conterio, M.T. Dove, J.S.O. Evans, D.A. Keen, L. Peters, M.G. Tucker, Colossal positive and negative thermal expansion in the framework material $\mathrm{Ag}_{3}\left[\mathrm{Co}(\mathrm{CN})_{6}\right]$, Science 319 (2008) 794-797.

[24] M.J. Conterio, A.L. Goodwin, M.G. Tucker, D.A. Keen, M.T. Dove, L. Peters, J.S.O. Evans, Local structure in $\mathrm{Ag}_{3}\left[\mathrm{Co}(\mathrm{CN})_{6}\right]$ : colossal thermal expansion, rigid unit modes and argentophilic interactions, J. Phys.: Condens. Matter 20 (2008) 255225.

[25] R.H. Baughman, S. Stafström, C. Cui, S.O. Dantas, Materials with negative compressibilities in one or more dimensions, Science 279 (1998) 1522-1524.

[26] R. Lakes, K.W. Wojciechowski, Negative compressibility, negative Poisson's ratio, and stability, Phys. Stat. Sol. B 245 (2008) 545-551.

[27] A.B. Cairns, A.L. Goodwin, Negative linear compressibility, Phys. Chem. Chem. Phys. 17 (2015) 20449-20465.

[28] M. Jansen, Homoatomic $\mathrm{d}^{10}-\mathrm{d}^{10}$ interactions: their effects on structure and chemical and physical properties, Angew. Chem. Int. Ed. Engl. 26 (1987) 1098-1110.

[29] E. O'Grady, N. Kaltsoyannis, Does metallophilicity increase or decrease down group 11 ?? Computational investigations of $\left[\mathrm{Cl}-\mathrm{M}-\mathrm{PH}_{3}\right]_{2}(\mathrm{M}=\mathrm{Cu}, \mathrm{Ag}, \mathrm{Au},[111])$, Phys. Chem. Chem. Phys. 6 (2004) 680-687.

[30] K.E. Bessler, L.A.d.P. Calzavara, V.M. Deflon, E. Niquet, Bis( $\mu$-tricyanomethanido) tetrakis(triphenylphosphine)dicopper(I), Acta Cryst. E 57 (2001) m522-m523.

[31] S.J. Hunt, M.J. Cliffe, J.A. Hill, A.B. Cairns, N.P. Funnell, A.L. Goodwin, Flexibility transition and guest-driven reconstruction in a ferroelastic metal-organic framework, CrystEngComm 17 (2016) 361-369.

[32] L. Pauling, P. Pauling, A trireticulate crystal structure: trihydrogen cobalticyanide and trisilver cobalticyanide, Proc. Natl. Acad. Sci. USA 60 (1968) 362-367.

[33] R. Haser, B. Bonnet, J. Roziere, Caractéristiques spectroscopiques des liaisons hydrogène $\mathrm{N}-\mathrm{H}-\mathrm{N}$ très fortes. Études des acides $\mathrm{A}_{3} \mathrm{M}(\mathrm{CN})_{6},(\mathrm{~A}=\mathrm{H}, \mathrm{D} ; \mathrm{M}=\mathrm{Fe}, \mathrm{Co})$ par spectroscopie de vibration, J. Mol. Struct. 40 (1977) 177-189.

[34] D.A. Keen, M.T. Dove, J.S.O. Evans, A.L. Goodwin, L. Peters, M.G. Tucker, The hydrogen-bonding transition and isotope-dependent negative thermal expansion in $\mathrm{H}_{3} \mathrm{Co}(\mathrm{CN})_{6}$, J. Phys.: Condens. Matter 22 (2010) 404202.

[35] C. Lind, Two decades of negative thermal expansion research: where do we stand? Materials 5 (2012) 1125-1154.

[36] A.A. Coelho, TOPAS-academic, version 4.1 (computer software), Tech. rep., Coelho Software, Brisbane.

[37] P.W. Stephens, Phenomenological model of anisotropic peak broadening in powder diffraction, J. Appl. Cryst. 32 (1999) 281-289.

[38] A. Ratuszna, G. Małecki, Crystal structure of cubic $\mathrm{KMe}\left[\mathrm{M}(\mathrm{CN})_{6}\right]_{2}$ and monoclinic $\mathrm{Mn}_{3}\left[\mathrm{Fe}(\mathrm{CN})_{6}\right]_{2}$ with $\mathrm{Me}=\mathrm{Co}, \mathrm{Ni}, \mathrm{Cu} ; \mathrm{M}=\mathrm{Co}, \mathrm{Fe}$, Mater. Sci. Forum 321-324 (2000) 947-953.

[39] M.J. Cliffe, A.L. Goodwin, PASCal: a principal axis strain calculator for thermal expansion and compressibility determination, J. Appl. Cryst. 45 (2012) $1321-1329$.

[40] J.F. Nye, Physical Properties of Crystals, Oxford University Press, Oxford, 1957.

[41] V. Blum, R. Gehrke, F. Hanke, P. Havu, V. Havu, X. Ren, K. Reuter, M. Scheffler, Ab initio molecular simulations with numeric atom-centered orbitals, Comput. Phys. Commun. 180 (2009) 2175-2196.

[42] J.P. Perdew, K. Burke, M. Ernzerhof, Generalized gradient approximation made simple, Phys. Rev. Lett. 77 (1996) 3865-3868.

[43] A. Tkatchenko, M. Scheffler, Accurate molecular van der Waals interactions from ground-state electron density and free-atom reference data, Phys. Rev. Lett. 102 (2009) 073005 .

[44] A. Tkatchenko, R.A. DiStasio Jr., R. Car, M. Scheffler, Accurate and efficient method for many-body van der Waals interactions, Phys. Rev. Lett. 108 (2012) 236402.

[45] A. Ambrosetti, A.M. Reilly, R.A. DiStasio Jr., A. Tkatchenko, Long-range correlation energy calculated from coupled atomic response functions, J. Chem. Phys. 140 (2014) 18A508.

[46] J.D. Gale, GULP: a computer program for the symmetry-adapted simulation of solids, J. Chem. Soc. Faraday Trans. 93 (1997) 629-637.

[47] A.G. Sharpe, The Chemistry of Cyano Complexes of the Transition Metals, Academic Press, London, 1976.

[48] A. Widmann, H. Kahlert, H. Wulff, F. Scholz, Electrochemical and mechanochemical formation of solid solutions of potassium copper(II)/zinc(II) hexacyanocobaltate(III)/hexacyanoferrate(III) $\mathrm{KCu}_{\mathrm{x}} \mathrm{Zn}_{1-\mathrm{x}}[\mathrm{hcc}]_{\mathrm{x}}[\mathrm{hcf}]_{1-\mathrm{x}}$, J. Sol. St. Electrochem. 9 (2005) 380-389.

[49] S.J. Hibble, S.G. Eversfield, A.R. Cowley, A.M. Chippindale, Copper(I) cyanide: a simple compound with a complicated structure and surprising room-temperature reactivity, Angew. Chem. Int. Ed. 43 (2004) 628-630.

[50] M.J. Katz, K. Sakai, D.B. Leznoff, The use of aurophilic and other metal-metal 
interactions as crystal engineering design elements to increase structural dimensionality, Chem. Soc. Rev. 37 (2008) 1884-1895.

[51] S.S. Batsanov, Van der Waals radii of elements, Inorg. Mater. 37 (2001) 871-885.

[52] G.D. Barerra, J.A.O. Bruno, T.H.K. Barron, N.L. Allan, Negative thermal expansion, J. Phys.: Condens. Matter 17 (2005) R217-R252.

[53] S.J. Hibble, G.B. Wood, E.J. Biblé, A.H. Pohl, M.G. Tucker, A.C. Hannon, A.M. Chippindale, Structures and negative thermal expansion properties of the one-dimensional cyanides, CuCN, AgCN and AuCN, Z. Krist. 225 (2010) 457-462.

[54] T.A. Mary, J.S.O. Evans, T. Vogt, A.W. Sleight, Negative thermal expansion from 0.3 to $1050 \mathrm{~K}$ in $\mathrm{ZrW}_{2} \mathrm{O}_{8}$, Science 272 (1996) 90-92.

[55] J. Adamson, T.C. Lucas, A.B. Cairns, N.P. Funnell, M.G. Tucker, A.K. Kleppe, J.A. Hriljac, A.L. Goodwin, Competing hydrostatic compression mechanisms in nickel cyanide, Physica B 479 (2015) 35-40.

[56] X. Liu, J. Hermann, A. Tkatchenko, Many-body stabilization of non-covalent interactions: structure, stability, and mechanics of $\mathrm{Ag}_{3} \mathrm{Co}(\mathrm{CN})_{6}$ framework, J. Chem. Phys. 145 (2016) 241101.

[57] M. Calleja, A.L. Goodwin, M.T. Dove, Origin of the colossal positive and negative thermal expansion in $\mathrm{Ag}_{3}\left[\mathrm{Co}(\mathrm{CN})_{6}\right]$ : an ab initio density functional theory study, $\mathrm{J}$. Phys.: Condens. Matter 20 (2008) 255226.

[58] L. Magnko, M. Schweizer, G. Rauhut, M. Schutz, H. Stoll, H.-J. Werner, A comparison of metallophilic attraction in $\left(\mathrm{X}-\mathrm{M}-\mathrm{PH}_{3}\right)_{2}(\mathrm{M}=\mathrm{Cu}, \mathrm{Ag}, \mathrm{Au} ; \mathrm{X}=\mathrm{H}, \mathrm{Cl})-$ $\mathrm{PH}_{32}((\mathrm{M}=\mathrm{Cu}, \mathrm{Ag}, \mathrm{Au} ; \mathrm{X}=\mathrm{H}, \mathrm{Cl}))$, Phys. Chem. Chem. Phys. 4 (2002) 1006-1013.

[59] R.W. Munn, Rôle of the elastic constants in negative thermal expansion of axial solids, J. Phys. C: Solid State Phys. 5 (1972) 535-542.

[60] M.T. Dove, H. Fang, Negative thermal expansion and associated anomalous physical properties: review of the lattice dynamics theoretical foundation, Rep. Prog. Phys. 79 (2016) 066503

[61] H. Fang, M.T. Dove, K. Refson, Ag-Ag dispersive interaction and physical properties of $\mathrm{Ag}_{3} \mathrm{Co}(\mathrm{CN})_{6}$, Phys. Rev. B 90 (2014) 054302.

[62] P. Hermet, J. Catafesta, J.-L. Bantignies, C. Levelut, D. Maurin, A.B. Cairns, A.L. Goodwin, J. Haines, Vibrational and thermal properties of $\mathrm{Ag}_{3}\left[\mathrm{Co}(\mathrm{CN})_{6}\right]$ from first-principles calculations and infrared spectroscopy, J. Phys. Chem. C 117 (2013) $12848-12857$.

[63] J.A. Hill, A.B. Cairns, J.J.K. Lim, S.J. Cassidy, S.J. Clarke, A.L. Goodwin, Zerostrain reductive intercalation in a molecular framework, CrystEngComm 17 (2015) 2925-2928.

[64] R. Mittal, M. Zbiri, H. Schober, S.N. Achary, A.K. Tyagi, S.L. Chaplot, Phonons and colossal thermal expansion behavior of $\mathrm{Ag}_{3} \mathrm{Co}(\mathrm{CN})_{6}$ and $\mathrm{Ag}_{3} \mathrm{Fe}(\mathrm{CN})_{6}$, J. Phys.: Condens. Matter 24 (2012) 505404.

[65] K.K. Mishra, N. Salke, S.N. Achary, A.K. Tyagi, R. Rao, High pressure Raman spectroscopic study of $\mathrm{H}_{3} \mathrm{Co}(\mathrm{CN})_{6}$, in: AIP Conference Proceedings, vol. 1591, 2014, p. 125.

[66] A.B. Cairns, J. Catafesta, C. Levelut, J. Rouquette, A. van der Lee, L. Peters, A.L. Thompson, V. Dmitriev, J. Haines, A.L. Goodwin, Giant negative linear compressibility in zinc dicyanoaurate, Nat. Mater. 12 (2013) 212-216.

[67] C.H. Woodall, C.M. Beavers, J. Christensen, L.E. Hatcher, M. Intissar, A. Parlett, S.J. Teat, C. Reber, P.R. Raithby, Hingeless negative linear compression in the mechanocromic gold comples $\left[\left(\mathrm{C}_{6} \mathrm{~F}_{5} \mathrm{Au}\right)_{2}(\mu\right.$-1,4-diisocyanobenzene $\left.)\right]$, Angew. Chem. Int. Ed. 52 (2013) 9691-9694. 